\title{
A model for quick load analysis for monopile-type offshore wind turbine substructures
}

\author{
Signe Schløer ${ }^{1}$, Laura Garcia Castillo ${ }^{2}$, Morten Fejerskov ${ }^{2}$, Emanuel Stroescu $^{2}$, and Henrik Bredmose \\ ${ }^{1}$ DTU Wind Energy, Nils Koppels Allé, Building. 403, 2800 Kgs. Lyngby, Denmark \\ ${ }^{2}$ Universal Foundation, Langerak 17, 9220 Aalborg Øst, Denmark \\ Correspondence: Signe Schløer (s.schloer@gmail.com)
}

Received: 22 February 2017 - Discussion started: 6 March 2017

Revised: 1 November 2017 - Accepted: 12 November 2017 - Published: 5 March 2018

\begin{abstract}
A model for quick load analysis, QuLA, of an offshore wind turbine substructure is presented. The aerodynamic rotor loads and damping are pre-computed for a land-based configuration. The dynamic structural response is represented by the first global fore-aft mode only and is computed in the frequency domain with phases using the equation of motion. The model is compared to the state-of-the-art aeroelastic code Flex5. Both lifetime fatigue and extreme loads are considered in the comparison. In general there is good agreement between the two models. Some deviations for the sectional forces are explained in terms of the model simplifications. The differences in the sectional moments are found to be within $10 \%$ for the fatigue load case and $10 \%$ for the extreme load condition.
\end{abstract}

\section{Introduction}

In order to ensure cost-efficient offshore wind farms, it is necessary to optimize the design. Particularly the substructures are expensive and can, according to Offshore Wind Project Cost OutLook (2014), account for $20 \%$ of the total cost of energy.

It is often different companies who design the substructure and the wind turbine of an offshore wind turbine. The iteration process in which the design suppliers of the wind turbine and the substructure send design loads back and forth slows the design process down.

The process is already time-consuming since extensive load-case simulations in which different wind speeds and wave climates are combined have to be made. If instead a fully integrated simulation of the foundation and wind turbine is used, the design process will be faster and the number of uncertainties in the design will be reduced. However, this approach is not always possible because the wind turbine manufacturers often do not want to share information about their wind turbines. Instead, in the preliminary design phase, integrated simulation and optimization can be achieved and accelerated with a simplified description of the loading from wind and a simple but fast dynamic model. This allows for the optimization of the foundation in an early stage of the design.

Recently Schafhirt et al. (2015) combined a substructuring technique, which is based on the principle of superposition of impulse responses, with the power of modern generalpurpose graphics processing units to compute the response of an offshore wind turbine subject to rotor loads. This method to perform simplified analysis of offshore wind turbines was found to have the same accuracy as standard aeroelastic models for distinct output locations as the overturning moment in the bottom of the tower but is 40 times faster for the case in which only rotor loading on the substructure is considered.

Van der Tempel et al. (2005) presented a simple approach on how to speed up the fatigue load calculations by dividing the offshore wind turbine into a turbine clamped at hub height with no support structure dynamics and one with a support structure. The analysis was linearized and made in the frequency domain by use of transfer functions, which according to Van der Tempel et al. (2005) is how the offshore oil and gas industry usually calculates the fatigue loads. The fatigue damage compared well to fatigue damage calculated in the time domain in the aeroelastic tool Bladed, with a difference of approximately $8 \%$. 
Smilden et al. (2016) also presented a simple model, but in which the focus was to improve the performance of the control system. The model therefore also includes a wind model, drivetrain, and a controller possessing the main features of the wind turbine control system in addition to the mode-shape-based structural model. Smilden et al. (2016) included two tower mode shapes in the model.

In the present paper a model for quick load analysis, QuLA, is presented. This is a fast model for the calculation of dynamic loads of an offshore wind turbine tower and foundation. The wind loads are applied in a similar manner as Van der Tempel et al. (2005) while the structural model is based on a single mode shape. Compared to the models above, the wave kinematics are described in more detail without linearization and including wave non-linearity for extreme load cases. The model is therefore suitable both for fatigue and the ultimate limit state. Compared to Van der Tempel et al. (2005) the aerodynamic damping is included as a function of mean wind speed, instead of being independent of the wind speed.

In the present paper the foundation is bottom fixed; however, QuLA has been applied to a floating wind turbine too; see Lemmer et al. (2015) for preliminary results. The $10 \mathrm{MW}$ DTU reference wind turbine (Bak et al., 2013) from the Technical University of Denmark is considered and the foundation is the Mono Bucket foundation of Universal Foundation. ${ }^{1}$ The Mono Bucket consists of a shaft and a bucket as shown in Fig. 1. Compared to a monopile, the Mono Bucket has the advantage of very small noise impact during installation, reduced scour protection, and no need for a transition piece. So far a Vestas V90-3.0 MW offshore wind turbine was erected on a Mono Bucket foundation in November 2002 in Frederikshavn harbour, Denmark. In addition, a met mast foundation for the Horns Rev 2 site was installed in March 2009 and decommissioned successfully in 2015. Two other met mast foundations were installed at Forewind's Dogger Bank offshore wind site in September 2013. In order to make the Mono Bucket foundation commercial, an industrialization and production evolution is needed. A fast numerical model to calculate the dynamic loads of the foundation is one of the tools applied in that process.

This paper investigates how well QuLA performs by comparing the model against the aeroelastic code Flex5 (Øye, 1996). The paper opens with a presentation of QuLA. Further, two different methods to include the aerodynamic damping are discussed. Hereafter the metocean data and the three load cases considered in the analysis are presented. Finally, the sectional inline force and overturning moment in different sections in the Mono Bucket and tower are considered for the load cases, and both lifetime fatigue and extreme loads are analysed. The largest difference of $30 \%$ is found for the sectional inline force in the bottom of the Mono Bucket foundation, while the overturning moments compare

${ }^{1}$ http://universal-foundation.com/. well in most parts of the tower and Mono Bucket foundation, with the largest difference being $10 \%$. The design of the Mono Bucket foundation is confidential. Therefore, in this paper the results of the sectional forces and moments and response spectra are presented in normalized form.

This paper is part of a special issue of papers in Wind Energy Science and is an extended version of a previously published paper, (Schløer et al., 2016b), published with IOP (from The Science of Making Torque From Wind conference). In the previous paper only one method to calculate the aerodynamic damping was considered and details on how the damping was calculated was left out. Furthermore, only two load cases were considered in the comparison of QuLA to Flex 5 in the previously published paper. In the present paper the results are, compared to the previously published paper, improved mainly due to changes in the calculations of the aerodynamic damping and the addition of load case 1.3 to extend the analysis.

\section{The numerical model QuLA}

In QuLA, only the Mono Bucket foundation and wind turbine tower are considered and described as a simple Euler beam. On top of the beam a top mass, $M_{\text {top }}$, representing the rotor and nacelle is added. The top mass is placed at the same height as the centre of mass in the nacelle, $z_{N}, 2.75 \mathrm{~m}$ above the tower top, $z_{\mathrm{TT}}$, as illustrated in Fig. 2. The foundation is only considered down to the seabed and the stiffness of the soil and lid and skirt of the bucket is described using a coupled translational and rotational spring, $\mathbf{K}_{\mathrm{s}}$. The dynamic structural response is only represented by the first natural mode and the equation of motion is solved in the frequency domain.

The philosophy behind the model is to pre-calculate the aerodynamic forces in an aeroelastic model with a stiff foundation and tower for all considered wind speeds. Also, the aerodynamic damping is pre-calculated for all considered wind speeds. The aerodynamic forces and damping are subsequently reused several times in QuLA for different tower and substructure configurations. The pre-computed aerodynamic force and damping can be made for a land-based turbine configuration and can thus be established as part of the turbine specifications by the manufacturer independent of the choice of substructure.

\subsection{The external forces}

The external forces are the distributed wave force and the turbulent wind force as seen in Fig. 2. The pre-calculated rotor shaft loads are applied as a time varying point force, $F_{\text {aero }}$, and overturning moment, $M_{\text {aero }}$, at the centre of mass in the nacelle $z_{N}$. The force from the wind on the tower is also included and is calculated inside QuLA by the power 


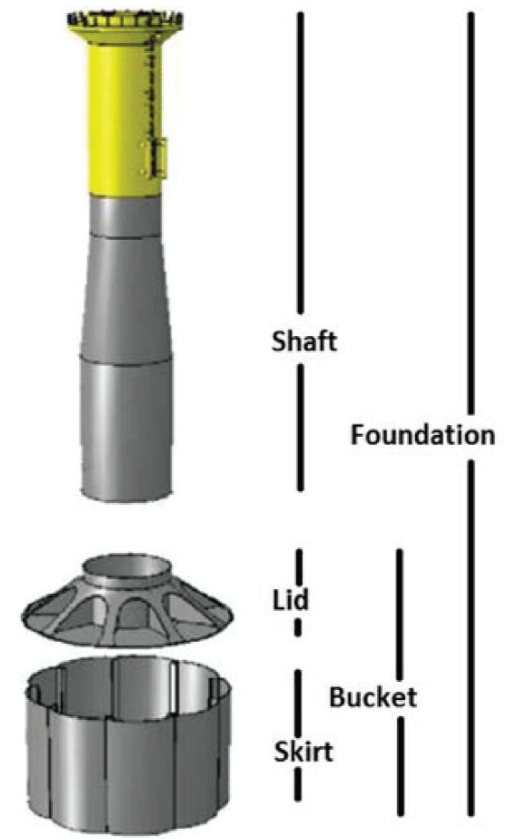

Figure 1. Mono Bucket foundation.

law from IEC61400-3 (2009):

$f_{\text {aero }}(x, t)=\frac{1}{2} \rho_{\mathrm{a}} C_{\mathrm{Da}} D\left(\left(\frac{x}{x_{n}}\right)^{\lambda} W(t)\right)^{2}$.

Usually the shear exponent is designated as $\alpha$, but since $\alpha$ in this paper represents the generalized coordinate, the shear exponent is instead designated as $\lambda$, with $\lambda=0.14$ in load case 1.2 and load case 1.3 and $\lambda=0.11$ in load case 6.1. Here $\rho_{\mathrm{a}}=1.225 \mathrm{~kg} \mathrm{~m}^{-3}$ is the density of air, $C_{\mathrm{Da}}=0.6$ is the aerodynamic drag coefficient, $D(z)$ is the diameter of the tower, and $W$ is the turbulent wind speed at the nacelle.

The wave kinematics and hydrodynamic force are also calculated inside QuLA. To enable fast calculations of the structural response, no stretching of the wave kinematics is applied and the wave kinematics are therefore only defined up to still water level (SWL).

In situations in which fatigue loads are considered, linear wave theory is often sufficient to describe the wave kinematics (Schløer et al., 2016a). For a known spectral shape (in this case JONSWAP) an irregular wave realization is characterized by the significant wave height $H_{\mathrm{S}}$ and the peak wave period $T_{\mathrm{p}}$. The linear irregular wave kinematics and loads are calculated in the frequency domain and afterwards transformed to the time domain using inverse fast Fourier transformation in order to include the non-linear terms in the hydrodynamic force. The distributed hydrodynamic load on the structure is calculated using Morison's equation:

$f_{\text {wave }}(z, t)=\rho C_{\mathrm{m}} A \dot{u}+\rho A \dot{u}+\frac{1}{2} \rho C_{\mathrm{D}} D u|u|$.
Here $\rho=1025 \mathrm{~kg} \mathrm{~m}^{-3}$ is the density of water, $A(x)$ is the cross-sectional area of the pile, and $D(z)$ is the diameter of the pile. The horizontal particle velocity and acceleration are denoted as $u$ and $\dot{u}$. The coefficients $C_{\mathrm{D}}$ and $C_{\mathrm{m}}$ are the drag and added mass coefficients, with $C_{\mathrm{M}}=1+C_{\mathrm{m}}$ being the inertia coefficient. The coefficients are functions of the Keulegan-Carpenter number, $K C$, and Reynolds number, $R e$, and are calculated following the recommendations in DNV-OS-J101 (2010). For irregular wave realizations $K C$ and $R e$ can, according to Sumer and Fredsøe (2006), be calculated from the standard deviation of the horizontal velocity at SWL and the mean wave period.

The hydrodynamic damping due to the structural motion is considered small and neglected. Therefore, it is the absolute velocities that are considered in the drag force (third term in Eq. 2).

The added mass coefficient, $C_{\mathrm{m}}$, is corrected for diffraction effects with the theory of MacCamy-Fuchs (MacCamy and Fuchs, 1954), which is valid for linear waves. The correction is important for waves with $D / L>0.2$, where $L$ is the wavelength. In a water depth of $50 \mathrm{~m}$ it corresponds to wave frequencies larger than approximately $f>0.19 \mathrm{~Hz}$. To include the diffraction effect, the added mass force is calculated in the frequency domain and afterwards transformed to the time domain.

In order to simultaneously include both the effect of wave irregularity and wave non-linearity in the structural analysis, IEC61400-3 (2009) suggests embedding a large non-linear stream function wave in the linear irregular wave time series to represent extreme waves. This is done in situations in which ultimate limit state (ULS) is considered. Following the work of Rainey (1989) and Rainey (1995), the Lagrangian particle acceleration $\mathrm{d} u / \mathrm{d} t$ is applied for these cases in the Morison equation instead of the Eulerian acceleration $\partial u / \partial t$ and further extended by the axial divergence correction term

$f_{\text {Rainey }}(z, t)=\rho A C_{\mathrm{m}} w_{z} u$,

which according to Manners and Rainey (1992) corrects for the assumption that the cylinder is slender in the vertical direction. Here the vertical particle velocity is denoted by $w$, and index " $z$ " means that the variable is differentiated with respect to $z$.

Finally a point force should, according to Rainey (1995), be added at the intersection with the water level

$F_{\mathrm{s}}(t)=-\frac{1}{2} \rho A C_{\mathrm{m}} \eta_{x} u^{2}$.

Here $\eta_{x}$ is the slope of the free surface elevation and represents the change of the free surface elevation along the pile diameter. This force can be seen as a slamming force.

The Rainey terms, Eqs. (3) and (4), are non-linear contributions to the Morison force and are therefore only added to the Morison Eq. (2) in situations in which a non-linear single 


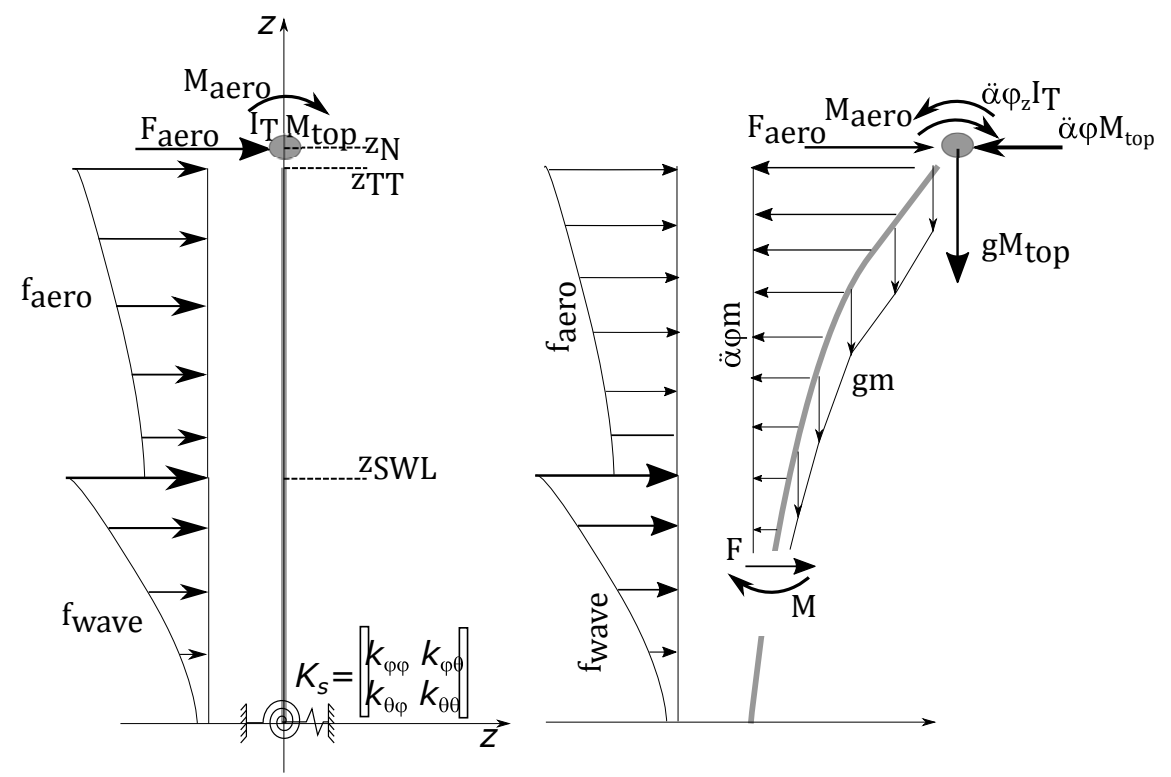

Figure 2. (a) Sketch of the beam and the external forces. (b) The external and internal forces that contribute to sectional force, $F$, and moment, $M$.

wave event is embedded in the irregular linear wave realization in the ULS analysis.

\subsection{The structural model}

The structural dynamic deflection of the Mono Bucket and tower, $u$, is represented by a shape function, $\varphi$, and a generalized coordinate $\alpha$ as $u=\alpha(t) \varphi(x)$. Shape functions are often introduced when the equation of motion of a system is solved to decrease the number of degrees of freedom in the system and thereby the computational time. Only one shape function in the fore-aft direction is considered in QuLA. While this may not provide an accurate representation of the full deformation, it is used here for the purpose of approximating the associated inertia loads for the sectional forces; see Eqs. (13)-(14). The shape function and the natural angular frequency, $\omega_{0}$, are found by considering a standard eigenvalue problem:

$$
\begin{aligned}
\mathbf{M} \ddot{\alpha} \underline{\varphi}+\mathbf{K} \alpha \underline{\varphi} & =0, \quad \text { where } \quad \alpha=\exp \left(i \omega_{0} t\right) \Leftrightarrow \\
-\mathbf{M} \omega_{0}^{2} \underline{\varphi}+\mathbf{K} \underline{\varphi} & =0 \Rightarrow \omega_{0}^{2} \underline{\varphi}=\mathbf{M}^{-1} \mathbf{K} \underline{\varphi} .
\end{aligned}
$$

The stiffness, $\mathbf{K}$, and mass matrix, $\mathbf{M}$, are calculated using the finite element method. Stiffness elements representing the stiffness from the soil-structure interaction, $K_{\mathrm{S}}$ in Fig. 2, are calculated in the geotechnical software tool Plaxis (Brinkgreve et al., 2016) and are added to the stiffness matrix in the bottom of the pile. The top mass and mass moment of inertia around the nacelle ( $y$ axis), $I_{T}$, are added to the mass matrix in the top of the pile. To get the correct first natural frequency it is important to define $M_{\text {top }}$ and $I_{T}$ at the same height as the centre of mass in the nacelle, $z_{N}$.
The structural dynamics are calculated with the equation of motion

$\ddot{\alpha} G_{\mathrm{M}}+\alpha G_{\mathrm{K}}+\dot{\alpha} G_{\mathrm{D}}=G_{\mathrm{F}}$.

In order for the model to be fast, the equation of motion is solved in frequency domain. In frequency domain the generalized coordinate can be expressed as

$\alpha=\sum_{j=1}^{N_{f}} \hat{\alpha}_{j} \exp \left(i \omega_{j} t\right)+c . c .$,

where $\hat{\alpha}_{j}$ is a complex number, $\omega_{j}$ is the smallest angular frequency in the time series, and c.c. is the complex conjugate. The phase information of $\alpha$ is retained in Eq. (7).

The equation of motion

$-\omega^{2} G_{\mathrm{M}} \hat{\alpha}+i \omega G_{\mathrm{D}} \hat{\alpha}+G_{\mathrm{K}} \hat{\alpha}=\hat{G}_{\mathrm{F}} \Leftrightarrow$

$\hat{\alpha}=\frac{\hat{G}_{\mathrm{F}}}{-\omega^{2} G_{\mathrm{M}}+i \omega G_{\mathrm{D}}+G_{\mathrm{K}}}$

then solves the linear response in frequency domain and can readily be transposed to the time domain using inverse fast Fourier transform. By solving the equation in frequency domain, the solution $\hat{\alpha}$ can then be solved at once for all time steps.

The generalized mass, $G_{\mathrm{M}}$, and stiffness, $G_{\mathrm{K}}$, can be obtained from Eq. (5a) by left-multiplication of $\varphi^{T}$ and are given as

$G_{\mathrm{M}}=\int_{z=0}^{z \mathrm{TT}} m \varphi(z)^{2} \mathrm{~d} z+M_{\mathrm{top}} \varphi\left(z_{N}\right)^{2}+I_{T} \varphi_{z}\left(z_{N}\right)^{2}$, 


$$
G_{\mathrm{K}}=\int_{z=0}^{z_{\mathrm{TT}}} E I \varphi_{z z}(z)^{2} \mathrm{~d} z .
$$

Here $m(z)$ is the distributed mass of the tower and Mono Bucket foundation, $\varphi_{z}$ is the angular deflection of the shape function, and $\varphi_{z z}$ is the curvature of the shape function. The stiffness factor is given by the modulus of elasticity, $E$, and the moment of inertia, $I$. Further, the generalized damping, $G_{\mathrm{D}}$, and generalized force, $G_{\mathrm{F}}$, are given as

$$
\begin{aligned}
G_{\mathrm{D}} & =\zeta \frac{2 G_{\mathrm{K}}}{\omega_{0}}+D_{\text {aero }}, \\
G_{\mathrm{F}} & =\int_{z=0}^{z_{\mathrm{SWL}}} \varphi f_{\text {wave }} \mathrm{d} z+F_{\mathrm{S}}+F_{\text {aero }} \varphi\left(z_{\mathrm{TT}}\right)+M_{\text {aero }} \varphi_{z}\left(z_{\mathrm{TT}}\right) \\
& +\int_{z_{\mathrm{SWL}}}^{z_{\mathrm{TT}}} \varphi f_{\text {aero }} \mathrm{d} z
\end{aligned}
$$

Here, $\zeta$ is the damping ratio representing structural damping, soil damping, and hydrodynamic radiation damping, and $D_{\text {aero }}$ is the aerodynamic damping coefficient.

After the equation of motion is solved, the sectional forces and moments can be calculated. The external and internal forces, which contribute to the sectional forces and moments are shown in Fig. 2 and the forces and moments are calculated with integration over the structure above the point of interest as

$$
\begin{aligned}
& F\left(z^{*}, t\right)=-\ddot{\alpha} \int_{z^{*}}^{z_{\mathrm{TT}}} m \varphi(z) \mathrm{d} z-\ddot{\alpha} M_{\mathrm{top}} \varphi\left(z_{N}\right) \\
& +\int_{z^{*}}^{z \mathrm{swL}} f_{\text {wave }} \mathrm{d} z+F_{\mathrm{s}}+F_{\text {aero }} \\
& +\int_{z^{*}}^{z \mathrm{TT}} f_{\text {aero }} \mathrm{d} z+\alpha g M_{\mathrm{top}} \varphi_{z}\left(z_{N}\right) \\
& +\alpha g \int_{z^{*}}^{z \mathrm{TT}} m \varphi_{z}(z) \mathrm{d} z \\
& M\left(z^{*}, t\right)=-\ddot{\alpha} \int_{z^{*}}^{z_{\mathrm{TT}}} m \varphi(z)\left[z-z^{*}\right] \mathrm{d} z-\ddot{\alpha} M_{\mathrm{top}} \varphi\left(z_{N}\right)\left[z_{n}-z^{*}\right] \\
& -\ddot{\alpha} I_{T} \varphi_{z}\left(z_{N}\right) \\
& +\int_{z^{*}}^{z \mathrm{SWL}} f_{\mathrm{wave}}\left[z-z^{*}\right] \mathrm{d} z+F_{\mathrm{s}}\left[z_{\mathrm{SWL}}-z^{*}\right] \\
& +M_{\text {aero }}+F_{\text {aero }}\left[z \text { TT }-z^{*}\right] \\
& +\int_{z^{*}}^{z \mathrm{TT}} f_{\mathrm{aero}}\left[z-z^{*}\right] \mathrm{d} z+\alpha M_{\mathrm{top}} g\left[\varphi\left(z_{N}\right)-\varphi\left(z^{*}\right)\right]
\end{aligned}
$$

$$
+\alpha g \int_{z^{*}}^{z \mathrm{TT}} m\left[\varphi\left(z_{\mathrm{TT}}\right)-\varphi(z)\right] \mathrm{d} z,
$$

where $g$ is the gravity. The first two terms in both equations are the contribution from the dynamics of the structure. When the equation of motion is solved, the Mono Bucket and tower are treated as a Euler beam, where the deflections are assumed small and only lateral loads are considered. Secondorder contributions from the bending of the beam are therefore neglected in the solution in order for the model to be fast. However, in the sectional forces and moment the contribution from gravity due to the bending of the beam is included, as stated in the last two terms in both equations. While this approach thus represents a difference in the forces applied for dynamics and sectional loads, it was found to improve the sectional loads in the comparison to Flex5.

\subsection{Shape function and eigenfrequency}

The complete shape function of both the tower and bucket foundation in Flex 5 is compared to the shape function of QuLA in Fig. 3. The shape functions are close to being identical. The deviation between the first natural frequency of the two models is $1 \%$. The difference is caused by differences in the models: in Flex5 the gravity's contribution to the bending of the pile is included in the equation of motion, which gives a larger moment of inertia and therefore a lower frequency. In QuLA the contribution of the gravity of both the top mass, representing the blades, hub, and nacelle, and the tower is only included in the sectional forces calculated after the equation of motion is solved.

\subsection{The aerodynamic damping}

As the structural dynamics is included in QuLA, it is also necessary to include the aerodynamic damping. If the structural motion is in the same direction as the wind velocity, the relative velocity that the aerodynamic forces are a function of decreases and thereby the forces also decrease. Since the aerodynamic forces are included as point forces in QuLA and since the equation of motion is solved in frequency domain, the aerodynamic damping can only be added as a viscous linear damping force, where the damping coefficient is a function of the mean wind speed.

Two different methods to calculate the damping coefficients are presented below and compared for load case 1.2 in Sect. 4.1.

\subsubsection{Standard deviation of pile displacement}

In this approach the target is to have the same standard deviation of the pile displacement at the top of the tower. Therefore, the tower top displacement has to be calculated in advance in Flex 5 or another aeroelastic model for all considered cases. In QuLA, when the equation of motion is solved, 


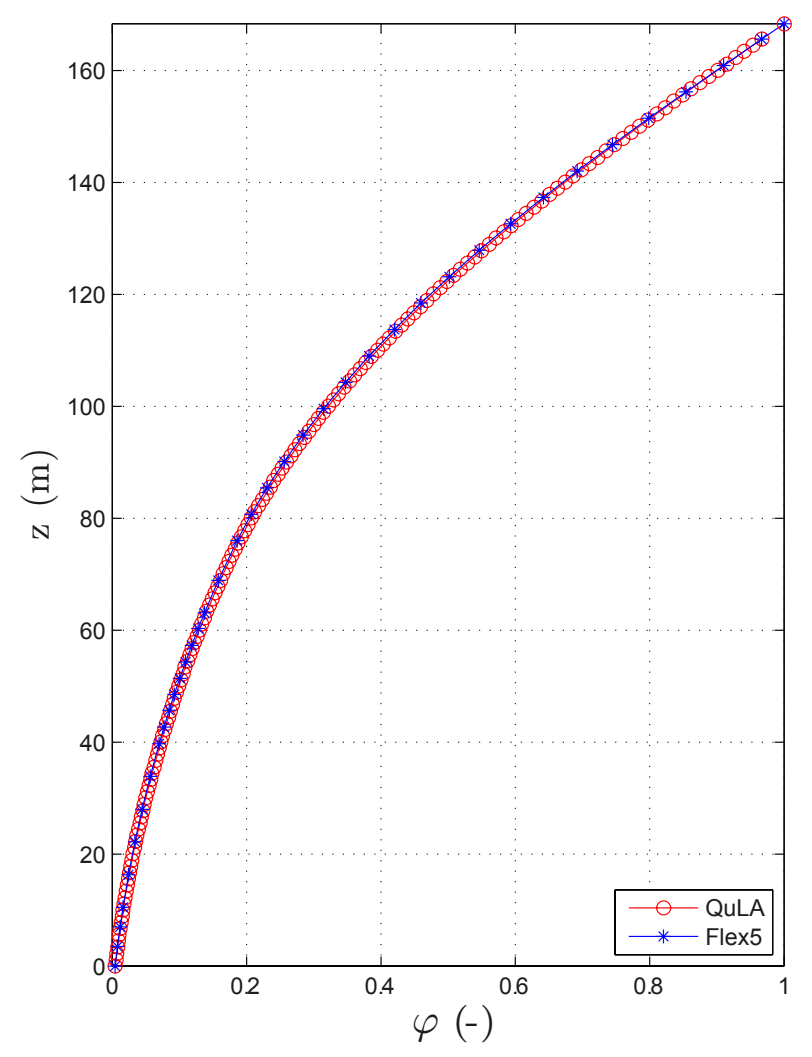

Figure 3. The shape function.

a loop is included, where the aerodynamic damping is increased until the standard deviation is the same for Flex 5 and QuLA. The standard deviation is calculated as

$\sigma=\sqrt{\overline{\left(u_{N N}-\overline{u_{N N}}\right)^{2}}}$

where $\mathrm{u}_{N N}$ is the tower top displacement.

In Figs. 4-5 the tower top displacements calculated in Flex5 and QuLA for $W=4.16$ and $W=14.55 \mathrm{~m} \mathrm{~s}^{-1}$ are shown for load case 1.2. For the small wind speed the two models compare very well; however, as the wind increases differences between the two models are more visible. This is due to differences in how the models are solved. In Flex5 the aerodynamic damping is a function of time, while in QuLA it is represented by a constant linear damping coefficient for each mean wind speed. Furthermore, in QuLA only one degree of freedom is used and the gravity's contribution to the deflection is not included in QuLA as mentioned in Sect. 2.3.

\subsubsection{Decay tests}

The aerodynamic damping force, $D_{\text {aero }}$, is calculated alternatively in Flex5 using decay tests as function of wind speed. To calculate the damping force, both turbulent and steady wind speeds are considered. For both cases two simulations are run: one in which a starting velocity of the wind turbine

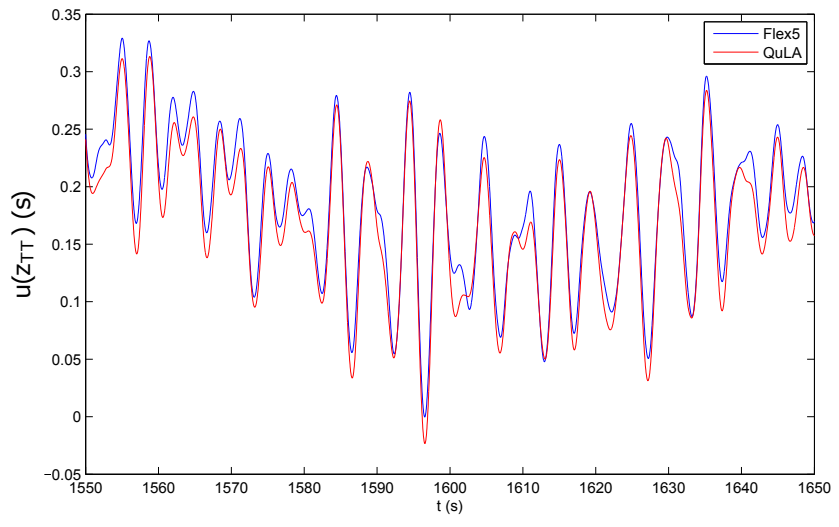

Figure 4. Tower top displacement for $W=4.16 \mathrm{~m} \mathrm{~s}^{-1}$. The aerodynamic damping in QuLA is based on the standard deviation of pile displacement.

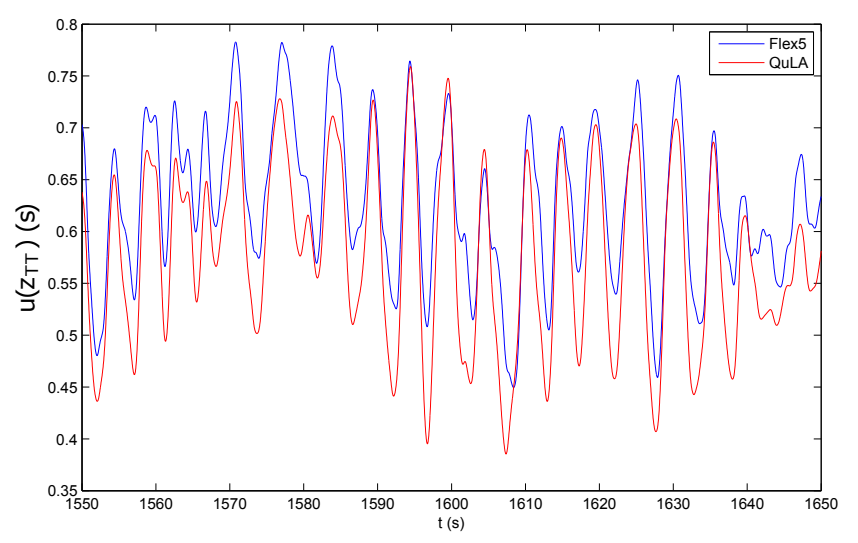

Figure 5. Tower top displacement for $W=14.55 \mathrm{~m} \mathrm{~s}^{-1}$. The aerodynamic damping in QuLA is based on the standard deviation of pile displacement.

tower and foundation is applied and one simulation without a starting velocity. The logarithmic decrement is calculated from the difference between the two simulations with and without a starting velocity.

All degrees of freedom are active; however, the rotor speed is kept constant and the pitch angle and rotational speed are given initial values in accordance with the wind speeds considered. According to Salzmann and Van der Tempel (2005) this method works well for constant speed wind turbines and compares well with other simple methods such as the Garrad method (Freris and Freris, 1990), Kühn's closed-form model (Kühn, 2001), or van der Tempel's method (Van Der Tempel, 2006). However, for a pitch-regulated wind turbine with varying rotor speed, which is the case for the DTU $10 \mathrm{MW}$ wind turbine, such simple methods cannot be applied to find the accurate logarithmic decrement above the rated wind speed at which the pitch regulation begins. However, the logarithmic decrement in QuLA can only be represented by a single value as a function of the mean wind speed. There- 

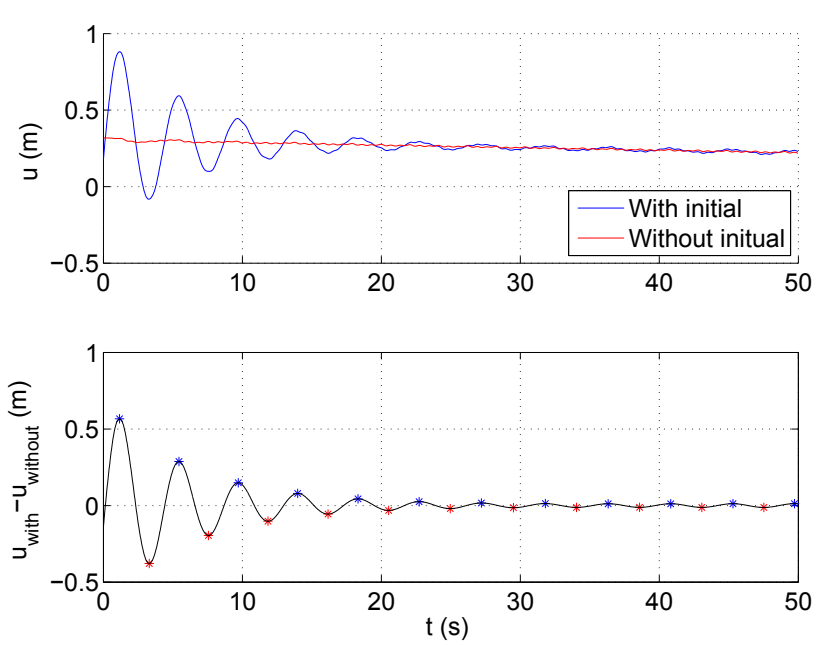

Figure 6. Decay test for a steady wind of $14 \mathrm{~m} \mathrm{~s}^{-1}$.

fore, the logarithmic decrement above the rated wind speed is still found by keeping the pitch and rotor speed constant.

The logarithmic decrement is calculated as

$\delta=\frac{1}{j} \log \left(\frac{\hat{a}_{1}}{\hat{a}_{j}}\right), \quad$ where $\quad j=2,3 \ldots$,

where $\hat{a}_{1}$ is the first peak considered in the time series and $\hat{a}_{j}$ is the $j$ th amplitude following $\hat{a}_{1}$. The relation between the logarithmic decrement, damping ratio $\zeta$, and the damping force $D_{\text {aero }}$ that is used in the dynamic analysis is

$\delta=\frac{2 \pi \zeta}{\sqrt{1-\zeta^{2}}}$

$D_{\text {aero }}=\zeta 2 \sqrt{G_{\mathrm{M}} G_{\mathrm{K}}}$,

where $G_{\mathrm{M}}$ and $G_{\mathrm{K}}$ are the generalized stiffness and mass; see Sect. 2.2.

In Figs. 6-7 the decay tests for a steady and turbulent wind speed of $14 \mathrm{~m} \mathrm{~s}^{-1}$ are shown. In the top panels the displacements in the top of the tower are shown for both the case in which the tower has an initial velocity of $U_{\text {init }} \sim 1.1 \mathrm{~m} \mathrm{~s}^{-1}$ and the one without an initial velocity, and in the bottom panels the subtracted displacements are shown. The logarithmic decrement has been estimated for the four peaks, both positive and negative, following the largest peak and then averaged,

In Fig. 8 the damping ratios as a function of both steady and turbulent wind speed are shown for three initial tower velocities. In Fig. 8 the average of the six curves is also shown. It can be observed that the damping ratio is very similar across the initial tower velocities.

\subsubsection{Comparison of the damping ratios}

In Fig. 9 the damping ratio as function of the wind speed from cut-in to cut-out wind speed is shown for the two dif-
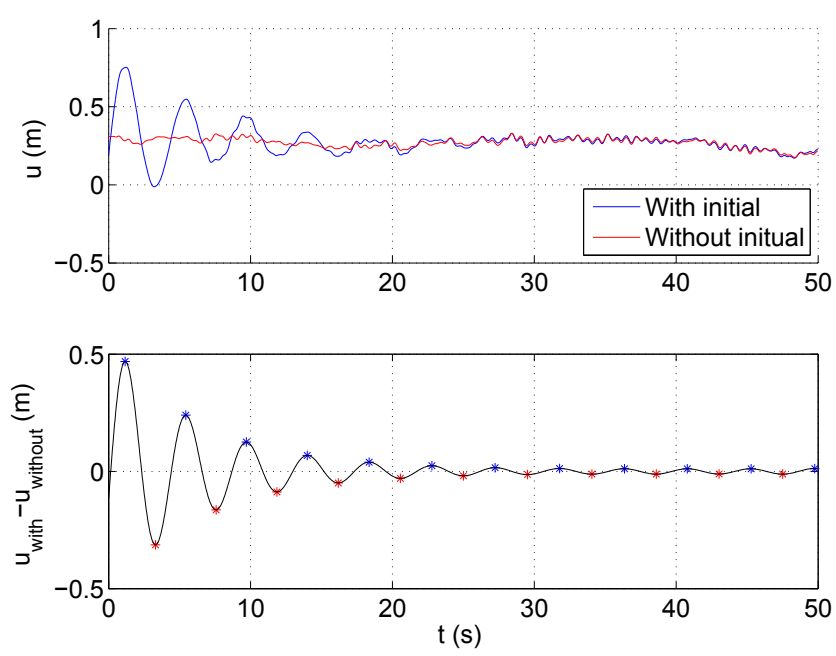

Figure 7. Decay test for a turbulent wind of $14 \mathrm{~m} \mathrm{~s}^{-1}$.

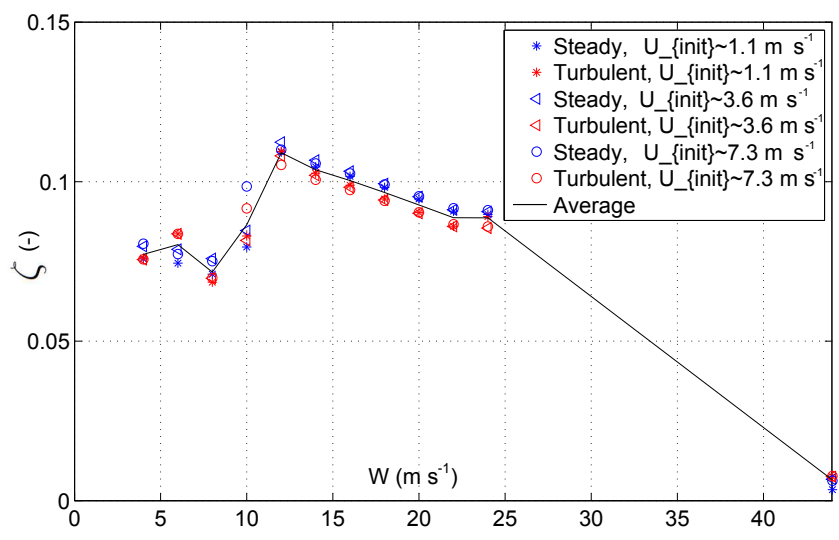

Figure 8. The damping ratio as a function of wind speed for different decay tests.

ferent methods used to calculate the aerodynamic damping force. The trend is similar for both damping curves. The damping ratio is constant for small wind speeds with a value between 7 and $8 \%$ for the decay tests and $2 \%$ for the tower top displacements but starts to increase before rated wind speed.

For the decay tests, the largest damping ratio of $10.5 \%$ is reached for a wind speed of $12 \mathrm{~m} \mathrm{~s}^{-1}$. Above the rated wind speed, the damping ratio decreases and is approximately $9 \%$ for a wind speed of $25 \mathrm{~m} \mathrm{~s}^{-1}$. For wind speeds between 10 and $17 \mathrm{~m} \mathrm{~s}^{-1}$, the damping ratio based on the tower top displacements increases from 2 to $10.3 \%$, after which it decreases and is $7 \%$ for a wind speed of $25 \mathrm{~m} \mathrm{~s}^{-1}$.

The damping ratio, based on decay tests, is larger than the one based on the standard deviation of the tower displacement, except for $W \sim 17 \mathrm{~m} \mathrm{~s}^{-1}$, where the damping based on the tower top displacement is largest. This might be because the standard deviation puts more weight on the low- 
amplitude motion. In the decay tests, the damping seems to become smaller for low-amplitude motion (see Fig. 7 lower plot) for $t>30 \mathrm{~s}$. The reason for the large increase in the damping ratio based on the standard deviation around $W=17 \mathrm{~m} \mathrm{~s}^{-1}$ can be because this method assumes that the tower deflection is the same for Flex5 and QuLA. This is not correct, as explained in Sect. 2.3. As the wind speed increases, the tower has a larger deflection and the contribution from the gravity is therefore larger. This contribution is not included when QuLA calculates the deflection.

Both methods require some preliminary work to calculate the viscous damping force to be used in QuLA. Either decay tests have to be made or the displacement in the top of the tower has to be calculated in an aeroelastic tool. However, as the foundation is very stiff, it is not believed that the foundation contributes significantly to the damping force. Therefore, the preliminary work can be made for a land-based wind turbine, and the aerodynamic damping can be reused several times as long as the wind turbine and tower are not changed.

How the different damping curves influence the performance of QuLA is investigated in Sect. 4.1.

\section{Metocean data and structure}

The load cases in the present analysis are based on the metocean data from the artificial site "K13 Deepwater Site" from the Upwind project (Fischer et al., 2010). The water depth is $h=50 \mathrm{~m}$. Three load cases are studied: load case 1.2, which considers the fatigue limit state (FLS), and load cases 1.3 and 6.1, which consider the ULS. The time series of each wind and sea state is $1 \mathrm{~h}$ long, which corresponds to six seeds of $600 \mathrm{~s}$. In load case 1.2 the wind turbine operates, and the wind speed ranges from 4 to $25 \mathrm{~m} \mathrm{~s}^{-1}$ with an interval of $2 \mathrm{~m} \mathrm{~s}^{-1}$ using a normal turbulence model. The already lumped sea states presented in Fischer et al. (2010) are used together with the wind speeds. Since fatigue loads are considered, the wind speed probability of occurrence is taken into account.

The wind speeds and the corresponding probability of occurrence $P_{r}$, turbulence intensity $I$, and sea states are stated in Table 1.

In load case 1.3 the wind turbine also operates and the wind speeds are the same as for load case 1.2, but the turbulence intensity is now based on an extreme turbulence model. The significant wave height is the expected wave height conditioned on the wind speed

$H_{\mathrm{s}}=E\left[H_{\mathrm{s}} \mid W\right]=\sum_{i} H_{\mathrm{s}, i} P_{\mathrm{rel}}$

where $P_{\text {rel }}$ is the relative probability of occurrence of each significant wave height conditioned on the considered wind speed. The range of peak wave periods appropriate to each $H_{\mathrm{S}}$ should be taken into account and the one resulting in the largest load should be used in the ULS analysis. Further, if

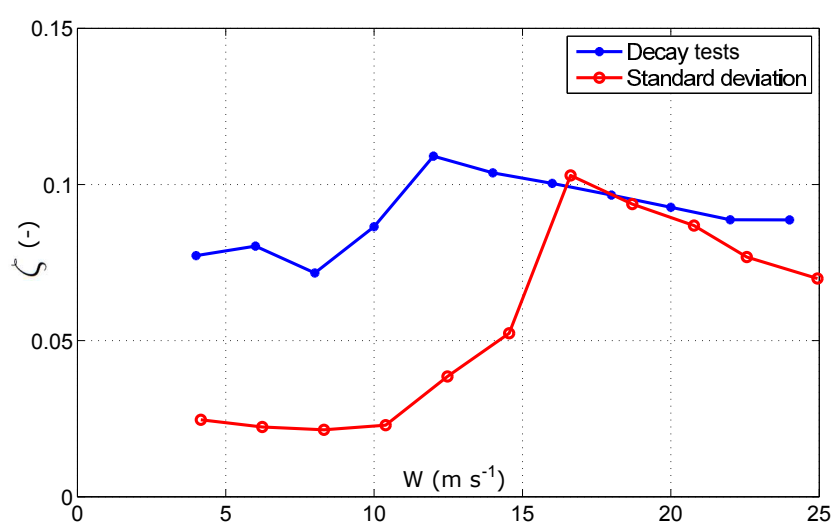

Figure 9. The damping ratio as a function of wind speed for the two methods to calculate the damping.

the peak wave period corresponding to the first natural frequency, $f_{1}=1 / T_{\mathrm{p}}$, is inside the considered range, this wave period should also be considered. The same applies to higher harmonics of the wave peak period, i.e. multiples of the peak wave frequency, $2 f_{\mathrm{p}}$ and $3 f_{\mathrm{p}}$, as this will cause a larger excitation of the structure. In the present analysis, the largest and smallest wave peak period that occur are considered. The wind speed, turbulence intensity, and corresponding $H_{\mathrm{S}}$ and $T_{\mathrm{p}}$ values are stated in Table 2 . Also, the periods in between the smallest and largest $T_{\mathrm{p}}$ value, for which the frequency or its multiples are equal to the first natural frequency, are considered. However, due to confidential design, these frequencies are not written in the table, but a "+" indicates for which wind speeds they occur.

In load case 6.1 the wind turbine is parked and the wind speed is $44.03 \mathrm{~m} \mathrm{~s}^{-1}$. The corresponding sea state has a significant wave height of $H_{\mathrm{s}}=9.40 \mathrm{~m}$ and a peak period of $T_{\mathrm{p}}=10.87 \mathrm{~s}$.

In ULS situations an irregular linear wave time series of $1 \mathrm{~h}$ length plus $100 \mathrm{~s}$ of transient time is first created. For every $600 \mathrm{~s}$ the largest wave in the interval is replaced with a non-linear regular stream function wave with a wave height of $H=1.86 H_{\mathrm{s}}$ (IEC61400-3, 2009). The corresponding wave period should according to IEC61400-3 (2009), be chosen as the period in the interval

$11.1 \sqrt{H_{\mathrm{s}} / g}<T<14.3 \sqrt{H_{\mathrm{s}} / g}$,

which results in the largest load. In the present analysis, six wave periods from $11.1 \sqrt{H_{\mathrm{s}} / g}$ to $14.3 \sqrt{H_{\mathrm{s}} / g}$ were considered for load case 6.1. It was found that for the present structure the largest load occurred for the smallest wave period: $T=11.1 \sqrt{H_{\mathrm{s}} / g}=10.87 \mathrm{~s}$ in load case 6.1. In load case 1.3 the same ratio, $T=11.1 \sqrt{H_{\mathrm{s}} / g}$, is also used.

The wind turbine is the $10 \mathrm{MW}$ DTU reference wind turbine (Bak et al., 2013). The wind turbine has a rated wind speed of $11.4 \mathrm{~m} \mathrm{~s}^{-1}$ and a rated rotor speed of $9.6 \mathrm{rpm}$. The 
Table 1. The wind speeds and the corresponding probability of occurrence, turbulence intensity, and sea states for load case 1.2.

\begin{tabular}{l|rrrr}
\hline $\begin{array}{l}W \\
\left(\mathrm{~m} \mathrm{~s}^{-1}\right)\end{array}$ & $\begin{array}{r}P_{\text {rel }} \\
(-)\end{array}$ & $\begin{array}{r}I \\
(-)\end{array}$ & $\begin{array}{r}H_{\mathrm{S}} \\
(\mathrm{m})\end{array}$ & $\begin{array}{r}T_{\mathrm{p}} \\
(\mathrm{s})\end{array}$ \\
\hline 4.16 & 0.11 & 0.29 & 1.10 & 5.88 \\
6.23 & 0.14 & 0.23 & 1.18 & 5.76 \\
8.31 & 0.16 & 0.20 & 1.31 & 5.67 \\
10.39 & 0.15 & 0.18 & 1.48 & 5.74 \\
12.47 & 0.13 & 0.17 & 1.70 & 5.88 \\
14.55 & 0.11 & 0.16 & 1.91 & 6.07 \\
16.62 & 0.08 & 0.15 & 2.19 & 6.37 \\
18.70 & 0.05 & 0.15 & 2.47 & 6.71 \\
20.78 & 0.03 & 0.14 & 2.76 & 6.99 \\
22.56 & 0.02 & 0.14 & 3.09 & 7.40 \\
24.94 & 0.01 & 0.14 & 3.42 & 7.80 \\
\hline
\end{tabular}

rotor diameter is $178.3 \mathrm{~m}$ and hub height is $119 \mathrm{~m}$. The rotor and nacelle mass are 229 and $446 \mathrm{t}$, respectively.

The first natural frequency of the structure is in between the $1 \mathrm{P}$ and $3 \mathrm{P}$ frequency interval of the wind turbine $(1 \mathrm{P}=0.115-0.159 \mathrm{~Hz})$. In both Flex5 and QuLA a logarithmic damping decrement $\delta=2 \pi \zeta=0.06$ is included to represent soil damping, structural damping of the Mono Bucket and tower, and hydrodynamic radiation damping.

\section{Results}

In order for QuLA to be a useful tool in the design process, the model has to be faster than a more advanced aeroelastic model. Before QuLA can be used, it is necessary to precalculate the stochastic point loads, $F_{\text {aero }}$ and $M_{\text {aero }}$, and the aerodynamic damping. Though once they are calculated they can be used repeatedly in the design process.

To calculate a single wind and sea state on a Microsoft Windows machine with a clock rate of $2.30 \mathrm{GHz}, \mathrm{QuLA}$ is 40 times faster than Flex5, while on a Linux cluster machine with a clock rate of $1.9 \mathrm{GHz}$, QuLA is 3.3 times faster. It is believed that this can be speeded up to a similar performance as with the Windows machine. QuLA is further parallelized and can on a HPC cluster calculate in parallel all 11 wind and sea states of load case 1.2 in approximately $45 \mathrm{~s}$.

\subsection{Fatigue limit state}

Load case 1.2 considers the fatigue limit state during operation. For this load case the different methods to calculate the aerodynamic damping are compared.

In Figs. 10-11 the probability of exceedance, $P$, of the positive peaks in the $1 \mathrm{~h}$ time series of the sectional forces and moments in five sections of the Mono Bucket and tower are shown for the case with $V=10.39 \mathrm{~m} \mathrm{~s}^{-1}, H_{\mathrm{s}}=1.48 \mathrm{~m}$, and $T_{\mathrm{p}}=5.74 \mathrm{~s}$. Only the deflection in the fore-aft direction is calculated in QuLA and therefore only the forces and mo- ments in the fore-aft direction are considered in the analysis. The forces and moments are normalized with the largest force and moment peak at the seabed in the Flex 5 calculation.

Considering the force peaks in the tower QuLA compares best to Flex 5 when the damping is based on decay tests (Fig. 10), while in the Mono Bucket it is when the damping is based on standard deviation of the tower top displacements (Fig. 11). For both methods the difference between QuLA and Flex5 is largest in the Mono Bucket. Comparing the moments, which are usually more relevant for the design, the two models are very similar, with the largest difference at the seabed. Considering the exceedance probability curves of the moment peaks, the differences in the damping are easy to identify. Compared to Flex5 the moment peaks of QuLA are smallest when the damping is based on decay tests, while the opposite is seen when the damping is based on standard deviation of the tower top displacement.

In fatigue analysis, equivalent loads, $L_{\mathrm{eq}}$, can be used as a reference loading and represent one load range value that for a certain number of cycles, $N_{\mathrm{eq}}=10 \times 10^{6}$, results in the same damage level as the history of investigated fatigue loads. It is calculated as

$L_{\mathrm{eq}}=\left(\sum_{j}\left(\sum_{i} \frac{N_{\mathrm{s}, i} S_{i}^{m}}{N_{\mathrm{eq}}}\right) P_{\mathrm{rel}, j}\right)^{\frac{1}{\mathrm{~m}}}$.

In Eq. (21) $N_{\mathrm{s}, i}$ is the number of occurrences of each stress range, $S_{i}$, for the considered wind and sea state, $j$. The equivalent loads are calculated for the sectional forces and moments using a Wöhler exponent of $m=4$ and taking the wind and sea states probability of occurrence into account.

In Figs. 12-13 the ratio of the equivalent forces and moments of QuLA to those of Flex5 (QuLA / Flex5) throughout the tower and Mono Bucket are shown, both when the aerodynamic damping force is based on decay tests and standard deviation of tower top displacements.

The variation in the ratios in the tower and Mono Bucket is the same for the two damping methods, but it is clear whether the damping based on the decay tests results in the best agreement with Flex 5 results. Instead of having ratios around 1 in most parts of the structure, which is seen when the damping is based on decay tests, the ratios are approximately 1.15 when the damping is based on tower top displacements. However, with both damping methods the difference between the equivalent forces of QuLA and those of FLex 5 increases from the top of the monopile and down to the bottom. Near the seabed the difference between the equivalent forces of QuLA to those of Flex5 is 0.7. Here the largest difference is for the aerodynamic damping based on decay tests.

This change from the tower to the monopile can be explained by considering a sequence of the time series and response amplitude spectra of the $1 \mathrm{~h}$ time series of the sectional forces at the intersection between the Mono Bucket 
Table 2. The wind speeds and the turbulence intensity and sea states for load case 1.3.

\begin{tabular}{l|rrrrcc}
\hline $\begin{array}{l}W \\
\left(\mathrm{~m} \mathrm{~s}^{-1}\right)\end{array}$ & $\begin{array}{r}I \\
(-)\end{array}$ & $\begin{array}{r}H_{\mathrm{s}} \\
(-)\end{array}$ & $\begin{array}{r}T_{\mathrm{p}, \min } \\
(\mathrm{m})\end{array}$ & $\begin{array}{r}T_{\mathrm{p}, \max } \\
(\mathrm{s})\end{array}$ & $\begin{array}{r}T_{\mathrm{p}} \text { for } f_{1}=1 / T_{\mathrm{p}} \\
(\mathrm{s})\end{array}$ & $\begin{array}{r}T_{\mathrm{p}} \text { for } f_{1}=2 / T_{\mathrm{p}} \\
(\mathrm{s})\end{array}$ \\
\hline 4.16 & 0.82 & 5.88 & 4 & 11 & + & + \\
6.23 & 0.90 & 5.76 & 4 & 11.5 & + & + \\
8.31 & 1.05 & 5.67 & 4 & 11.5 & + & + \\
10.39 & 1.23 & 5.74 & 4 & 11.0 & + & + \\
12.47 & 1.46 & 5.88 & 5 & 9 & - & - \\
14.55 & 1.72 & 6.07 & 5 & 8 & - & - \\
16.62 & 2.07 & 6.37 & 5 & 9 & - & + \\
18.70 & 2.38 & 6.71 & 5 & 10 & - & - \\
20.78 & 2.80 & 6.90 & 5 & 8 & - & - \\
22.56 & 3.13 & 7.40 & 7 & 9 & - & + \\
24.94 & 3.58 & 7.80 & 7 & 10 & - & + \\
\hline
\end{tabular}
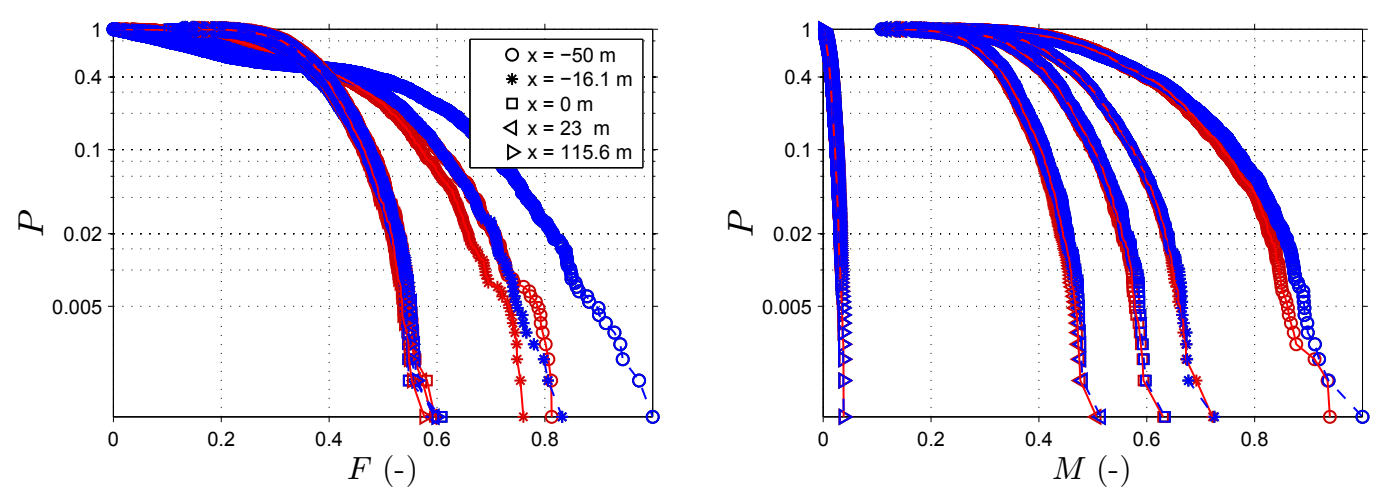

Figure 10. Probability of exceedance of the positive peaks in the time series of the sectional forces and moments for load case 1.2. Aerodynamic damping based on decay tests. The forces and moments are normalized with the largest force and moment peak at the seabed in the Flex5 calculation. Blue: Flex5. Red: QuLA.

foundation and tower ( $26 \mathrm{~m}$ above SWL) and at the seabed as seen in Figs. 14-15. The aerodynamic damping forces are based on decay tests. The forces are due to the wind and sea state with a wind speed of $10.39 \mathrm{~m} \mathrm{~s}^{-1}$ since this is found to contribute the most to the equivalent loads. The force time series are normalized with the largest force at the seabed in the Flex 5 calculations.

The energy around the first natural frequency is captured well by QuLA. Using Flex5 a big amount of energy is also found at the second natural frequency of the tower and Mono Bucket - in particular at the seabed. Since QuLA only has 1 degree of freedom and thus only one natural mode, no energy is observed in QuLA at this frequency. The main part of the modal energy of the second natural frequency is distributed in the Mono Bucket, which explains why the difference between the two models at the second natural frequency is largest at the seabed and why the ratio of the equivalent forces in Figs. 12-13 decreases throughout the Mono Bucket. This difference could be reduced by including a second degree of freedom in QuLA, as was done by Smilden et al. (2016). However, this will also double the complexity of the model, and focus has been to develop a very simple and fast model.

The difference between the equivalent moments in the Mono Bucket varies. Considering the ratios when the damping in QuLA is based on decay tests, the ratio changes from 1 to 1.05 from SWL to approximately $20 \mathrm{~m}$ above the seabed, where after the equivalent loads of QuLA at the seabed it again becomes smallest with a value of 0.93 relative to those of Flex5. The same trend is seen when the damping is based on tower top displacements, but a factor of approximately 0.15 should be added to the ratios. The reason there is such a difference between the equivalent forces and moments is that the moments not only depend on the size of the overlying forces but also on the size of the moment arm.

The different results obtained with the two methods to calculate the damping must be because only the decay tests are based on Flex 5 results, while the method with the tower top displacements is based on the assumption that the tower deflection is the same for Flex 5 and QuLA, which is not correct for all wind speeds. In the ULS analysis in the next section, the damping is therefore based on the decay tests. 

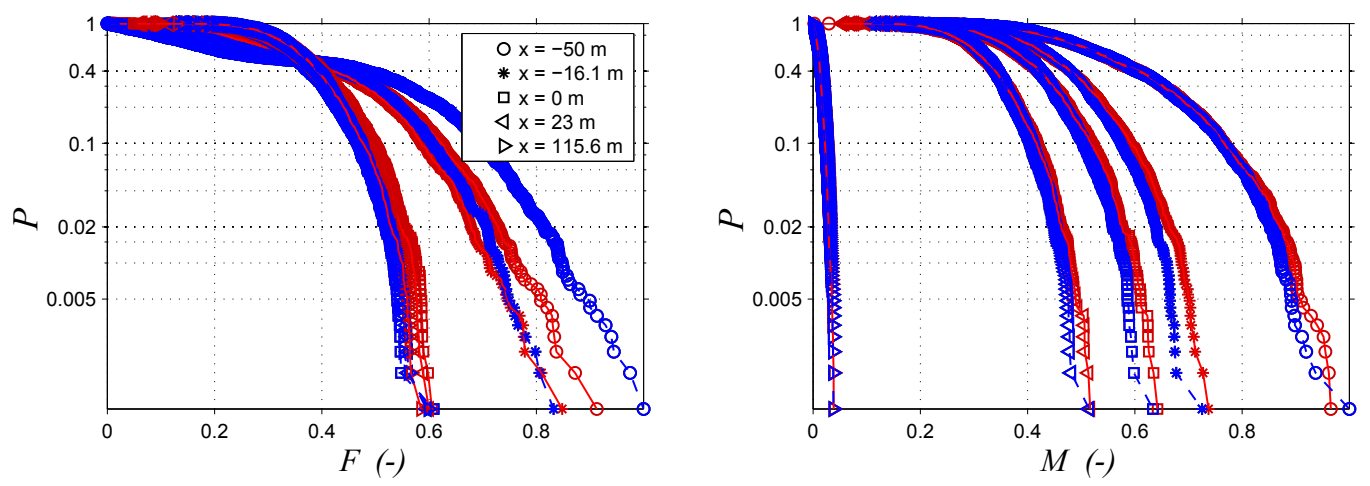

Figure 11. Probability of exceedance of the positive peaks in the time series of the sectional forces and moments for load case 1.2. Aerodynamic damping based on standard deviation of tower top displacement. The forces and moments are normalized with the largest force and moment peak at the seabed in the Flex5 calculation. Blue: Flex5. Red: QuLA.
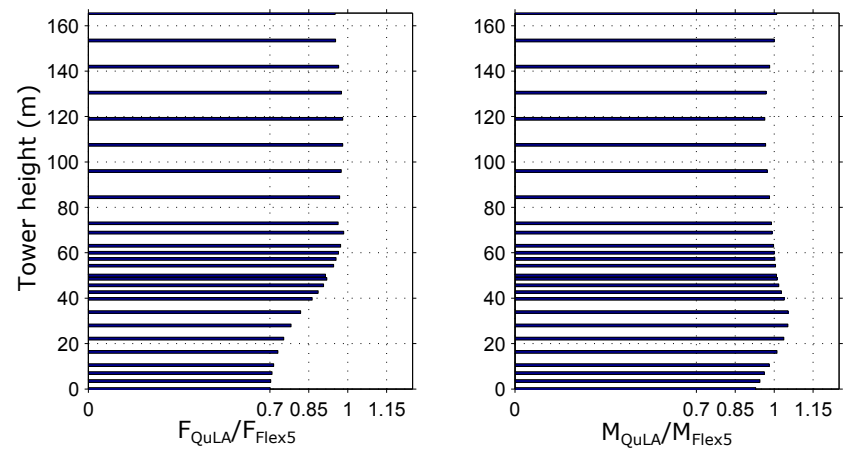

Figure 12. The ratio of the equivalent loads of QuLA to those of Flex 5 for load case 1.2 in all sections in the tower and Mono Bucket. Aerodynamic damping based on decay tests.
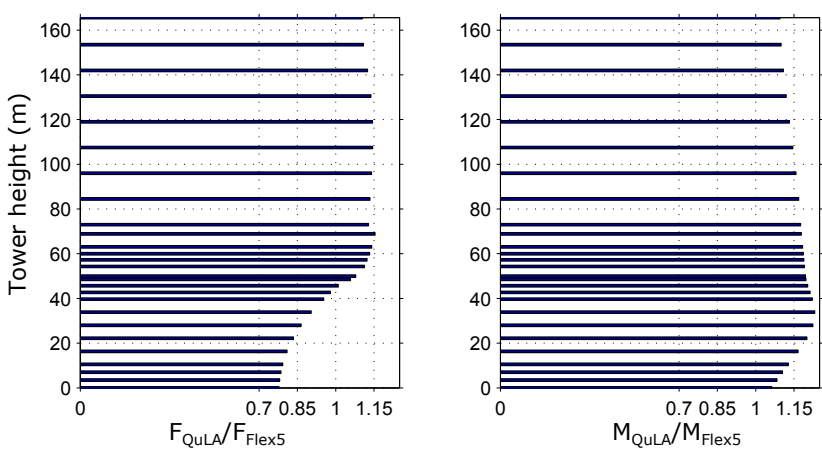

Figure 13. The ratio of the equivalent loads of QuLA to those of Flex 5 for load case 1.2 in all sections in the tower and Mono Bucket. Aerodynamic damping based on standard deviation of tower top displacement.

In the comparison of the equivalent loads of QuLA and Flex5, it is important to note that instead of the equivalent load ratio, the damage ratio could also be considered, which differs from the equivalent load ratio by the power of the
Wöhler exponent, $m$. Thus, the difference between the models is larger with that measure.

\subsection{Ultimate limit state}

Load cases 1.3 and 6.1 consider the ULS. To calculate the ultimate loads the $1 \mathrm{~h}$ time series of the forces and moments for each wind and sea state in the load case are divided into $6 \times 600 \mathrm{~s}$ intervals. In each interval the largest load is found and the average of these six loads is calculated. This approach is consistent with the IEC 61400-3 code, clause 7.5.1 for load case 1.3. For load case 6.1a, clause 7.5.1 states that six $1 \mathrm{~h}$ realizations should be considered, unless it can be demonstrated that the extreme response is not affected by application of shorter realizations. Constrained wave methods are mentioned as one way of enabling shorter realizations. This approach has been adopted for the present study. For some realizations, we found that the largest loads occurred at events outside of the embedded constrained wave. This is further discussed in Sect. 4.2.2.

\subsubsection{Load case 1.3}

In load case 1.3 the wind turbine operates.

In Fig. 16 the probability of exceedance, $P$, of the positive force peaks and moment peaks in the $1 \mathrm{~h}$ time series with $W=12.5 \mathrm{~m} \mathrm{~s}^{-1}, H_{\mathrm{s}}=1.46 \mathrm{~m}$, and $T_{\mathrm{p}}=9 \mathrm{~s}$ in five sections of the Mono Bucket and tower are shown. In the tower the forces and moments compare well. In the Mono Bucket a large difference between the forces is seen, which is due to the excitation of the second structural frequency in Flex 5 as was seen for load case 1.2. The difference in the forces also influences the moments at the seabed, where Flex 5 has the largest moment.

Considering the ratios of the ultimate limit states of QuLA to those of Flex 5 in Fig. 17, the same is seen. In the tower, the differences between the ultimate sectional forces and moments of QuLA and Flex5 are not more than 2 and $4 \%$, re- 

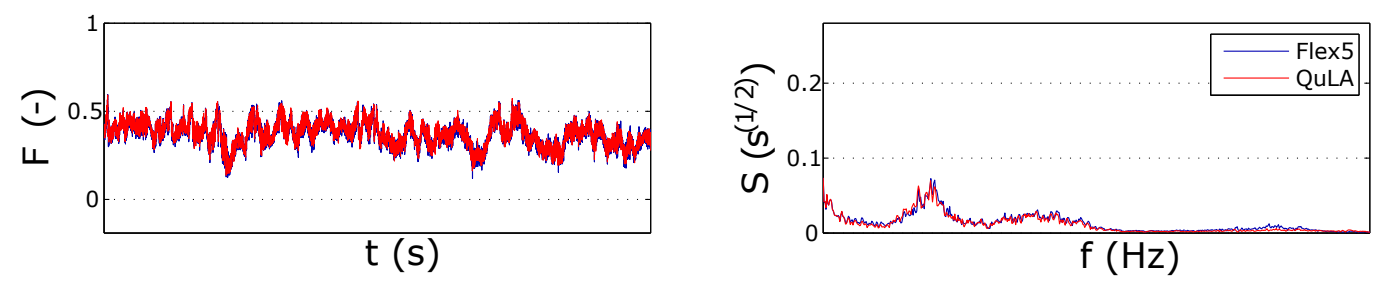

Figure 14. Sectional force $26 \mathrm{~m}$ above the SWL for load case 1.2. The force time series are normalized with the largest force at the seabed in the Flex 5 calculations.
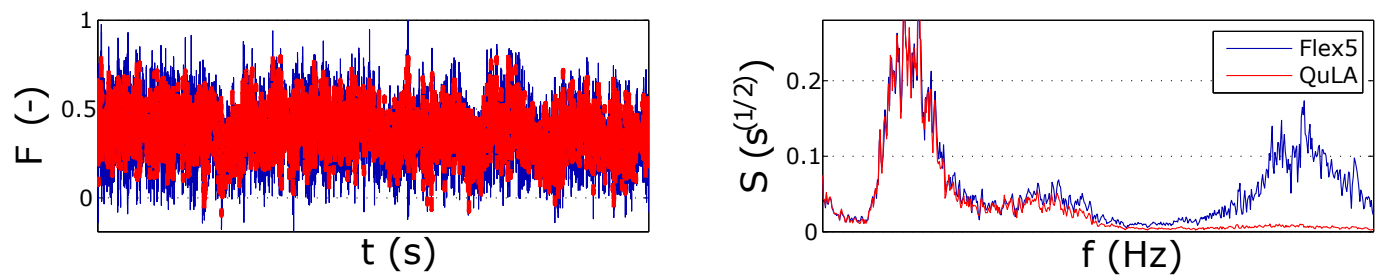

Figure 15. Sectional force at seabed for load case 1.2. The force time series are normalized with the largest force at the seabed in the Flex5 calculations.
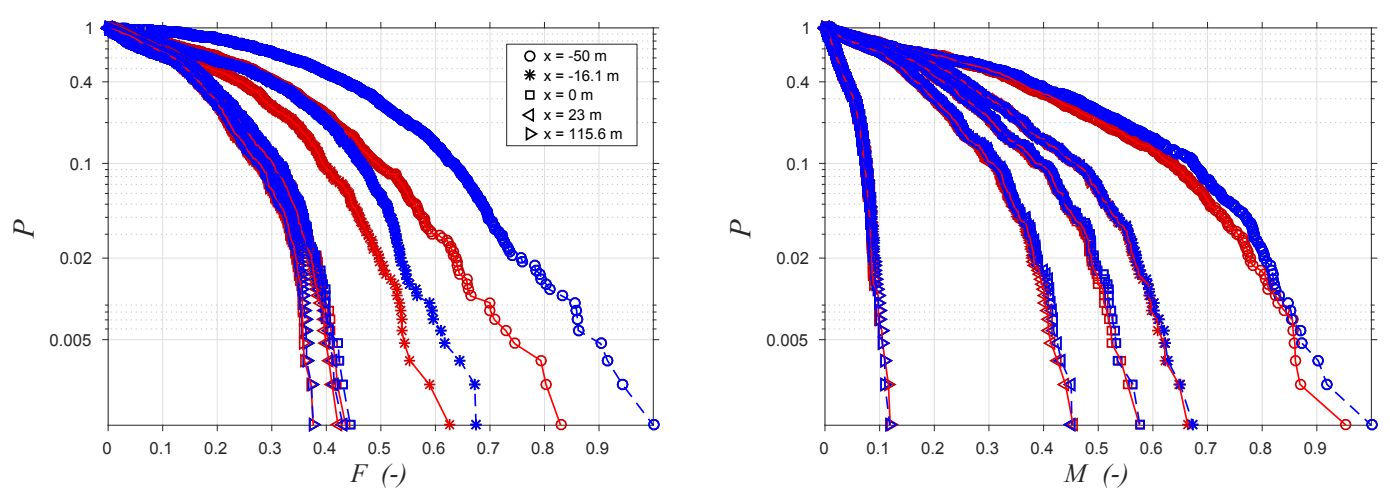

Figure 16. Probability of exceedance of the positive peaks in the time series of the sectional forces and moments for load case 1.3. The forces and moments are normalized with the largest force and moment peak at the seabed in the Flex5 calculation. Blue: Flex5. Red: QuLA.
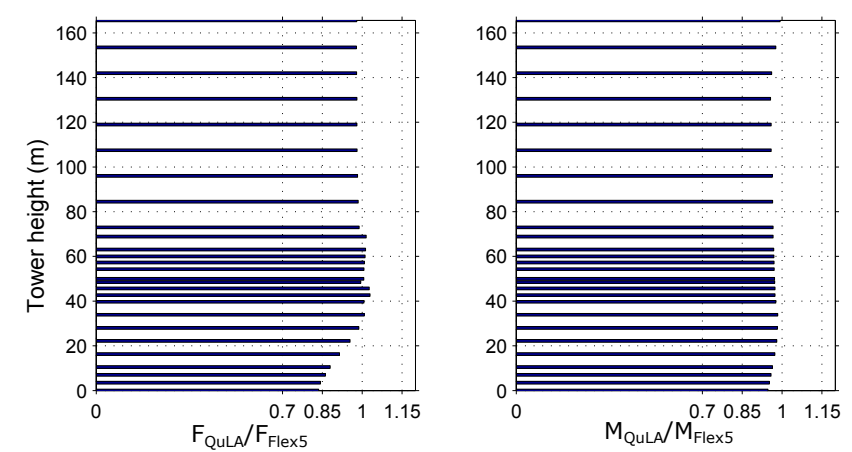

Figure 17. The ratio of the ultimate loads of QuLA to those of Flex 5 for load case 1.3 in all sections in the tower and Mono Bucket.

spectively. Flex5 has the largest ultimate moments in all sections, while the ultimate sectional forces of Flex5 are largest in the top of the tower and the ultimate sectional forces of QuLA are largest in the bottom of the tower. In the Mono Bucket FLex 5 has the largest ultimate forces due to the excitation of the second natural frequency. The difference between the models increases from the top to the bottom of the Mono Bucket and at the seabed the ratio is 0.85 . The effect of the second natural frequency is also visible in the ultimate moments, but the effect is not as strong since the forces in the tower still contribute more to the moment at the seabed, where the ratio between the two models is 0.95 . Usually the moment is more relevant for the design than the sectional force since it contributes more dominantly to the local stress.

\subsubsection{Load case 6.1}

Load case 6.1 considers a storm condition. The wind turbine is therefore parked, and the aerodynamic force and damping 

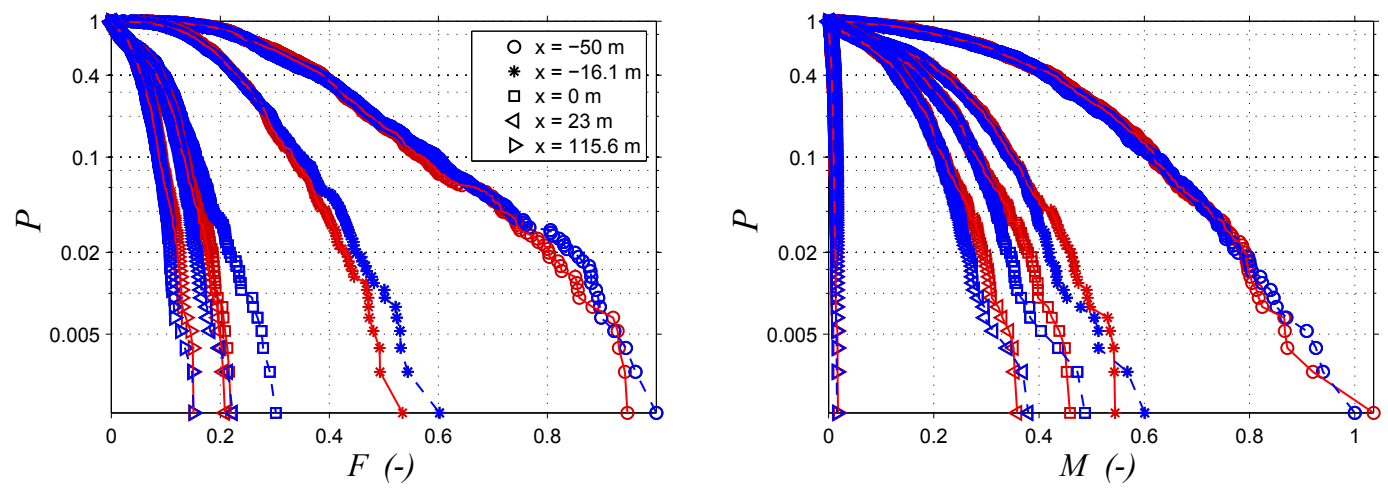

Figure 18. Probability of exceedance of the positive peaks in the time series of the sectional forces and moments for load case 6.1. The forces and moments are normalized with the largest force and moment peak at the seabed in the Flex5 calculation. Blue: Flex5. Red: QuLA.
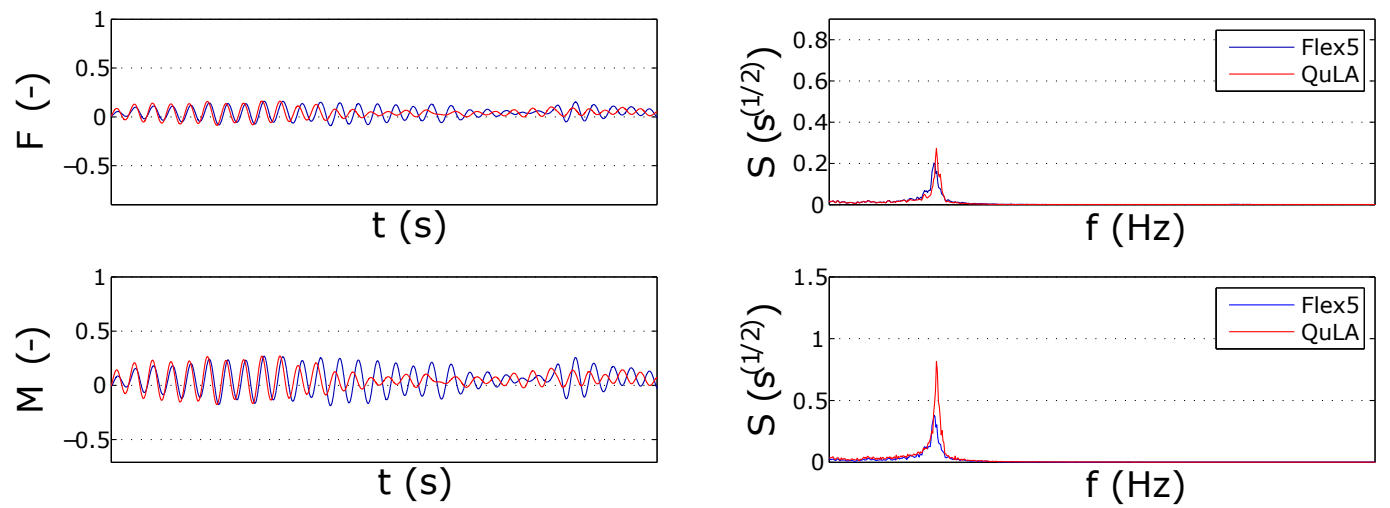

Figure 19. Sectional force and moment $26 \mathrm{~m}$ above the SWL for load case 6.1. The force and moment time series are normalized with the largest force and moment at the seabed in the Flex5 calculations.
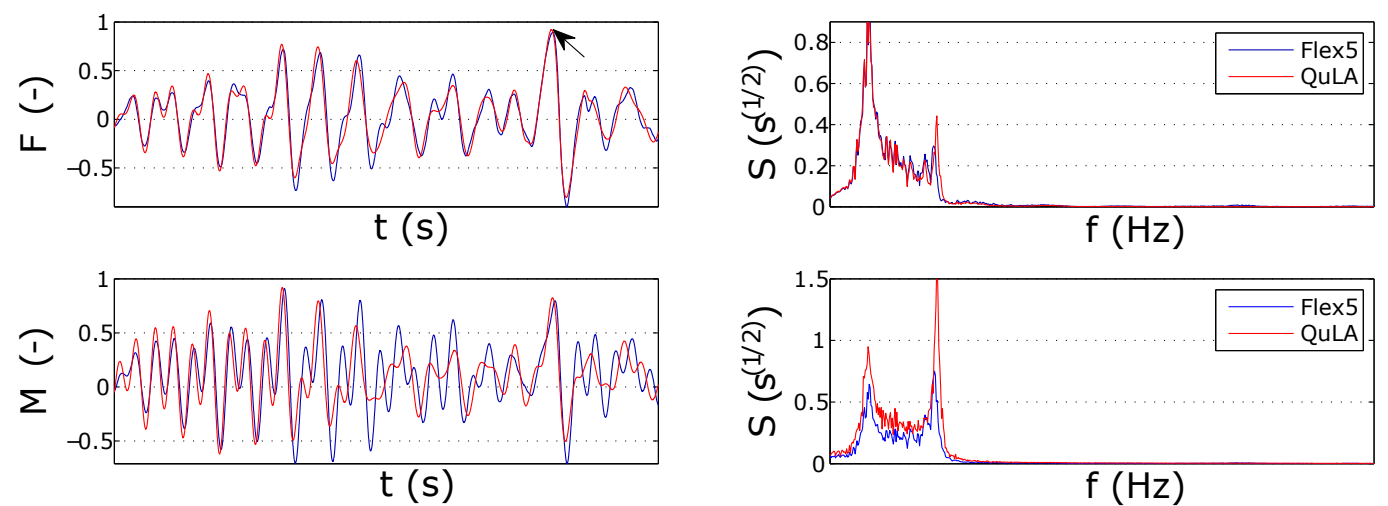

Figure 20. Sectional force and moment at the seabed for load case 6.1. The force and moment time series are normalized with the largest force and moment at the seabed in the Flex5 calculations.

are therefore small. The contribution from the wave force is thus expected to be significant.

In Fig. 18 the probability of exceedance, $P$, of the positive peaks in the $1 \mathrm{~h}$ time series of the sectional forces and moments in five sections of the Mono Bucket and tower are seen. Note that the six embedded stream function waves are part of the exceedance probability curve.

QuLA has the largest force peaks for high probability of exceedance, while Flex 5 has the largest force peaks for low probability of exceedance; however, in the tower, the probability of the force peaks are quite equal. At SWL there is 
a large difference between the curves of the two models, in particular for $P<0.03$. The peaks of Flex 5 are largest, which is caused by the Wheeler stretching in Flex5, which stretches the wave kinematics up to the free surface elevation instead of only being defined to SWL as in QuLA. In the Mono Bucket $26 \mathrm{~m}$ above the seabed, the difference between the two models is still significant but smaller. At the seabed the force curves of the two models are again quite equal.

The probability curves of the moments of the two models are more equal in all five sections. Particularly the largest moments, which are important in ULS, compare well. To compare the dynamics of the two models, a sequence of the time series and response amplitude spectra of the $1 \mathrm{~h}$ time series of the sectional forces and moments at the intersection between the tower and Mono Bucket and at the seabed are considered (Figs. 19-20). In the tower, the energy of the force and moment is located around the first natural frequency and it is clear that QuLA contains the most energy at this frequency. This is opposite to the time series, which indicate that the response of Flex 5 contains the most energy. However, this does not account for the whole time series, which the spectra are based on.

At the seabed, the energy is located both at the wave peak frequency and at the first natural frequency. The energy distribution of the force is very similar in the two models, while for the moments QuLA contains the most energy. In the time series the forces of the two models are very similar when a stream function wave is embedded into the wave realization - indicated with an arrow in the figure. However, for the chosen sequence of the time series the moments are not largest when the stream function wave is embedded. Instead the moments are largest in the beginning of the time sequence where the wave kinematics are described using linear wave theory. This means that for the stiffness and natural frequency of this foundation, the linear wave kinematics can also result in the largest moments. In other parts of the time series, though, the embedded stream function wave results in the largest overturning moment at the seabed. Still, this shows that the dynamic forces caused by the structural motion - and not only the static forces - are important in ULS. Furthermore, the presence of larger loads in some linear-wave-driven events indicate that for a full design study longer realizations should be included following the IEC design code. For the present study, though, this has been omitted since it does not affect the comparison between QuLA and Flex5.

The ratios of the ultimate loads of QuLA to those of Flex 5 are seen in Fig. 21. In the top of the tower the ultimate sectional forces in QuLA are largest with a ratio of 1.04, while just above SWL the two models result in the same ultimate sectional force. Around SWL there is an increase in the difference between the two models and the ratio of the ultimate sectional forces of QuLA to those of Flex5 reduces to 0.7. This is due to Wheeler stretching not applied in QuLA. However, the difference between the models decreases down through the Mono Bucket and at the seabed the models are
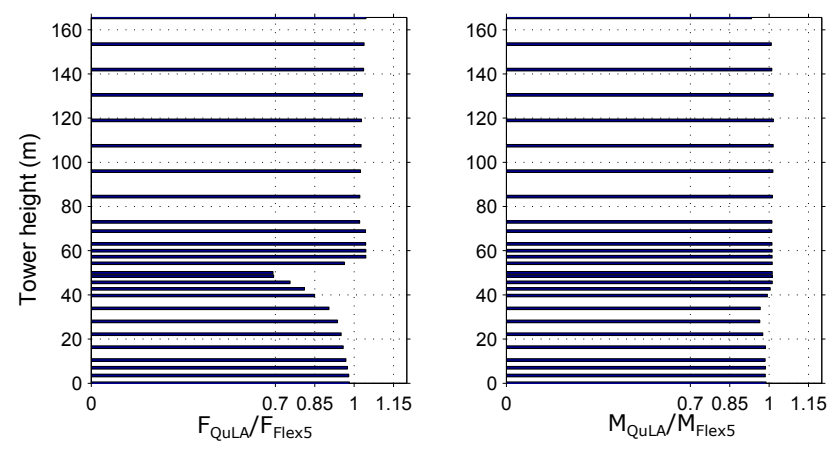

Figure 21. The ratio of the ultimate loads of QuLA to those of Flex 5 for load case 6.1 in all sections in the tower and Mono Bucket.

very close to each other with a ratio of 0.99 . This is expected since the wave force in load case 6.1 is the largest contributor to the sectional force, and the force at the seabed is the sum of the distributed force, which is calculated in same way in the two models, though not distributed equally.

With a ratio of approximately 1.02 , the difference between the ultimate sectional moments of the two models is more or less constant in all sections in the tower, with those of QuLA being largest. In the Mono Bucket the difference between the two models increases a little just below SWL due to the missing Wheeler stretching in QuLA. However, at the seabed the ratio is 0.99 .

\section{Conclusions}

A model, QuLA, to make fast linear response calculations of the foundation and tower of an offshore wind turbine has been presented. The model solves the equation of motion in the frequency domain and uses precalculated aerodynamic forces and damping as a function of the wind speed. Two methods to calculate the aerodynamic damping to be used in QuLA were presented. One based on decay tests calculated in Flex 5 and one in which the target was to have the same standard deviation of the tower top displacement in Flex 5 and QuLA. The damping based on decay tests gave more correct results.

To investigate the performance of QuLA the model was compared to Flex5. The shape function and the first natural frequency of the two models are almost identical.

In the fatigue analysis with a decay-based damping, the ratio of the equivalent forces of QuLA to those of Flex 5 was found to be 0.95 in the tower, while the excitation of the second structural frequency in Flex 5 results in a larger difference in the Mono Bucket. At the seabed the equivalent forces of QuLA are smallest with a ratio of 0.7. Considering the equivalent moments, which are often more important, the values of QuLA vary, with a ratio between 0.95 and 1.05, from those of Flex5. It would be possible to include a second degree of freedom in QuLA. This would improve the results 
of QuLA but would essentially also double the complexity of the model.

In the ultimate load analysis, the ratio of both ultimate forces and moments varies between 0.98 and 1.04 in most sections. This difference is due to differences in the dynamic response of the two models and shows that for ULS not only the extreme waves but also the dynamics of the structure are important. At mean water level, though, the missing Wheeler stretching in QuLA results in much smaller ultimate forces. This difference could be improved by including Wheeler stretching in the model, which would decrease the computational speed of the model though.

The proposed model of this paper presents a fast model with good accuracy, especially for the sectional moments. The analysis indicates that in the early stage of the design phase a simple dynamic model can be used in the iterative process to make a preliminary design of the foundation and wind turbine tower. After this, a full aeroelastic model can be used to verify the design and optimize it further. Combined use of a fast and accurate model might even be applied to enhance this optimization further.
Data availability. The model code was developed as part of a large research project and cannot be shared. The design of the Mono Bucket foundation is confidential. The model results are therefore not publicly available. However, some data can be shared by contacting the main author of this paper. 
Appendix A: Nomenclature

A Cross-sectional area of pile $\left(\mathrm{m}^{2}\right)$

$C_{\mathrm{D}} \quad$ Hydrodynamic drag coefficient

$C_{\mathrm{Da}} \quad$ Aerodynamic drag coefficient

$C_{\mathrm{m}} \quad$ Hydrodynamic added mass coefficient

$C_{\mathrm{M}} \quad$ Hydrodynamic inertia coefficient

$D \quad$ Pile diameter (m)

$D_{\text {aero }} \quad$ Aerodynamic damping force $\left(\mathrm{kg} \mathrm{s}^{-1}\right)$

$E \quad$ Modulus of elasticity $\left(\mathrm{N} \mathrm{m}^{-2}\right)$

$f \quad$ Frequency $(\mathrm{Hz})$

$f_{1} \quad$ First natural frequency $(\mathrm{Hz})$

$f_{\mathrm{p}} \quad$ Peak frequency $(\mathrm{Hz})$

$f_{\text {wave }} \quad$ Hydrodynamic distributed force $\left(\mathrm{N} \mathrm{m}^{-1}\right)$

$f_{\text {Rainey }} \quad$ Distributed Rainey force $\left(\mathrm{N} \mathrm{m}^{-1}\right)$

$F_{\text {aero }} \quad$ Pre-calculated rotor force $(\mathrm{N})$

$F \quad$ Force $(\mathrm{N})$

$F_{\mathrm{S}} \quad$ Rainey point force $(\mathrm{N})$

$g \quad$ Gravity $\left(\mathrm{m} \mathrm{s}^{-2}\right)$

$G_{\mathrm{D}} \quad$ Generalized damping $\left(\mathrm{kg} \mathrm{s}^{-1}\right)$

$G_{\mathrm{F}} \quad$ Generalized force (N)

$G_{\mathrm{K}} \quad$ Generalized stiffness $\left(\mathrm{kg} \mathrm{s}^{-2}\right)$

$G_{\mathrm{M}} \quad$ Generalized mass (kg)

$H_{\mathrm{S}} \quad$ Significant wave height (m)

$i \quad$ Imaginary units

I Area moment of inertia $\left(\mathrm{m}^{4}\right)$

$I_{T} \quad$ Mass moment of inertia $\left(\mathrm{kg} \mathrm{m}^{2}\right)$

K Stiffness matrix

$K C \quad$ Keulegan-Carpenter number

$\mathbf{K}_{\mathrm{s}} \quad$ Translational and rotational soil spring matrix

$L \quad$ Wavelength (m)

$L_{\text {eq }} \quad$ Equivalent load $(\mathrm{N})$ or $(\mathrm{Nm})$

$m \quad$ Distributed mass $\left(\mathrm{kg} \mathrm{m}^{-1}\right)$

$m \quad$ Wöhler exponent

M Mass matrix

M Moment (Nm)

$M_{\text {aero }} \quad$ Pre-calculated rotor moment (Nm)

$M_{\text {top }} \quad$ Top mass $(\mathrm{kg})$

$N_{\text {eq }} \quad$ No. of cycles

$N_{\mathrm{s}, i} \quad$ No. of occurrences of each stress range

$P \quad$ Probability of occurrence

$P_{\text {rel }} \quad$ Relative probability of occurrence

Re Reynolds number

SWL Still water level (m)

$S_{i} \quad$ Stress range $(\mathrm{N})$ or $(\mathrm{Nm})$
Time (s)

$T_{\mathrm{p}} \quad$ Peak wave period (s)

$u \quad$ Horizontal particle velocity $\left(\mathrm{m} \mathrm{s}^{-1}\right)$

$\dot{u} \quad$ Horizontal particle acceleration $\left(\mathrm{m} \mathrm{s}^{-2}\right)$

$u \quad$ Deflection (m)

$w \quad$ Vertical particle velocity $\left(\mathrm{m} \mathrm{s}^{-1}\right)$

$W \quad$ Turbulent wind speed $\left(\mathrm{m} \mathrm{s}^{-1}\right)$

$x \quad$ Horizontal coordinate $(\mathrm{m})$

$z_{N} \quad$ Centre of mass in the nacelle (m)

$z_{\mathrm{TT}} \quad$ Tower top $(\mathrm{m})$

$z \quad$ Vertical coordinate $(\mathrm{m})$

$\lambda \quad$ Shear exponent for power low; Eq. (1)

$\alpha \quad$ Generalized coordinate

$\delta \quad$ Logarithmic decrement

$\rho \quad$ Density of water $\left(\mathrm{kg} \mathrm{m}^{-3}\right)$

$\rho_{\mathrm{a}} \quad$ Density of air $\left(\mathrm{kg} \mathrm{m}^{-3}\right)$

$\omega \quad$ Angular frequency $\left(\operatorname{rad~s}^{-1}\right)$

$\omega_{0} \quad$ Natural angular frequency $\left(\operatorname{rad~s}^{-1}\right)$

$\sigma \quad$ Standard deviation

$\varphi \quad$ Shape function

$\zeta \quad$ Damping ratio 
Competing interests. The authors declare that they have no conflict of interest.

Special issue statement. This article is part of the special issue "The Science of Making Torque from Wind (TORQUE) 2016". It is a result of The Science of Making Torque from Wind (TORQUE 2016), Munich, Germany, 5-7 October 2016.

Acknowledgements. This research was carried out as part of the CEUF project, (Cost-Effective mass production of Universal Foundations for large offshore wind park), funded by a research project grant from the Innovation Fund Denmark. This support is gratefully acknowledged.

Edited by: Carlo L. Bottasso

Reviewed by: Michael Muskulus and one anonymous referee

\section{References}

Bak, C., Zahle, F., Bitsche, R., Kim, T., Yde, A., Henriksen, L., Natarajan, A., and Hansen, M.: Description of the DTU 10 MW Reference Wind Turbine, Tech. rep., DTU Wind Energy, 2013.

Brinkgreve, R., Kumarswamy, S., and Swolfs, W.: PLAXIS 2016, Tech. rep., Plaxis bv, 2016.

DNV-OS-J101: Design of Offshore Wind Turbines, Det Norske Veritas, 2010.

Fischer, T., de Vries, W., and Schmidt, B.: Upwind Design Basis. WP4: Offshore Foundations and Support Structures, Tech. rep., Project UpWind, Allmandring 5B, 70550 Stuttgart, Germany, 2010.

Freris, L. L. and Freris, L.: Wind energy conversion systems, vol. 3, Prentice Hall New York, 1990.

IEC61400-3: International Standard. Wind turbines - Part 3: Design requirements for offshore wind turbines, 1st Edn., 2009.

Kühn, M.: Dynamics and Design Optimation of Offshore Wind Energy Conversion Systems, PhD thesis, Delft University of Technology, 2001.

Lemmer, F., Müller, K., Pegalajar-Jurado, A., Borg, M., and Bredmose, H.: Qualification of innovative floating substructures for $10 \mathrm{MW}$ wind turbines and water depths greater than $50 \mathrm{~m}$, Tech. rep., LIFES50+, 2015.
MacCamy, R. and Fuchs, R.: Wave forces on piles: A diffraction theory, Tech. rep., U.S. Army Corps of Engineering, Beach Erosion Board, Tech. Memo. No. 69, 1954.

Manners, W. and Rainey, R.: Hydrodynamic Forces on Fixed Submerged Cylinders, P. Roy. Soc. Lond. A, 436, 13-32, 1992.

Øye, S.: FLEX4 simulation of wind turbine dynamics, in: 28th IEA Meeting of Experts Concerning State of the Art of Aeroelastic Codes for Wind Turbine Calculations, 1996.

Rainey, R.: A new equation for calculating wave loads on offshore structures, J. Fluid Mech., 204, 295-324, 1989.

Rainey, R.: Slender-Body Expressions for the Wave Load on Offshore Structures, P. Roy. Soc. Lond. A, 450, 391-416, 1995.

Salzmann, D. and Van der Tempel, J.: Aerodynamic damping in the design of support structures for offshore wind turbines, in: Paper of the Copenhagen Offshore Conference, 2005.

Schafhirt, S., Verkaik, N., Salman, Y., and Muskulus, M.: Ultrafast analysis of offshore wind turbine support structures using impulse based substructuring and massively parallel processors, in: The Twenty-fifth International Ocean and Polar Engineering Conference, International Society of Offshore and Polar Engineers, 2015.

Schløer, S., Bredmose, H., and Bingham, H.: The influence of fully nonlinear wave forces on aero-hydro-elastic calculations of monopile wind turbines, Mar. Struct., 50, 162-188, 2016a.

Schløer, S., Castillo, L. G., Fejerskov, M., Stroescu, E., and Bredmose, H.: A model for Quick Load Analysis for monopile-type offshore wind turbine substructures, in: Journal of Physics: Conference Series, vol. 753, p. 092008, IOP Publishing, 2016b.

Smilden, E., Horn, J.-T. H., Sørensen, A. J., and Amdahl, J.: Reduced Order Model for Control Applications in Offshore Wind Turbines, IFAC-PapersOnLine, 49, 386-393, 2016.

Sumer, M. and Fredsøe, J.: Hydrodynamics around cylindrical structures, World Scientific Publishing Co. Pte. Ltd., 2006.

Van Der Tempel, J.: Design of support structures for offshore wind turbines, PhD thesis, Delft University of Technology, 2006.

Van der Tempel, J., de Vries, W., and Wensink, G.: Frequency domain calculation of offshore wind turbine response to wind and wave loads, in: European offshore wind conference \& exhibition, Citeseer, 2005. 